\title{
Quantifying the Spatial Variations of Hyporheic Water Exchange at Catchment Scale Using the Thermal Method: A Case Study in the Weihe River, China
}

\author{
Junlong Zhang, ${ }^{1}$ Jinxi Song, ${ }^{1,2}$ Yongqing Long, ${ }^{1}$ Yan Zhang, ${ }^{1}$ Bo Zhang, \\ Yuqi Wang, ${ }^{3}$ and Yuanyuan Wang ${ }^{1}$ \\ ${ }^{1}$ College of Urban and Environmental Sciences, Northwest University, Xian 710127, China \\ ${ }^{2}$ State Key Laboratory of Soil Erosion and Dryland Farming on the Loess Plateau, Institute of Soil and Water Conservation, \\ Chinese Academy of Sciences, Yangling 712100, China \\ ${ }^{3}$ Fenner School of Environmental and Society, Australian National University, Canberra, ACT 2601, Australia
}

Correspondence should be addressed to Jinxi Song; jinxisong@nwu.edu.cn

Received 8 January 2017; Accepted 2 March 2017; Published 21 March 2017

Academic Editor: Xiaofeng Li

Copyright @ 2017 Junlong Zhang et al. This is an open access article distributed under the Creative Commons Attribution License, which permits unrestricted use, distribution, and reproduction in any medium, provided the original work is properly cited.

\begin{abstract}
Understanding the dynamics of hyporheic water exchange (HWE) has been limited by the hydrological heterogeneity at large catchment scale. The thermal method has been widely used to understand water exchange patterns in a hyporheic zone. This study was conducted in the Weihe River catchment in Shaanxi Province, China. A conceptual model was developed to determine water transfer patterns, and a one-dimensional heat diffusion-advection equation was employed to estimate vertical fluxes of ten different segments in the hyporheic zone in various ten segments of the catchment. The amount of water exchange varied from $78.47 \mathrm{~mm} / \mathrm{d}$ to $23.66 \mathrm{~mm} / \mathrm{d}$ and a decreasing trend from the upstream to downstream of catchment was observed. The spatial correlation of variability between the water exchange and distance is 0.62 . The results indicate that mountain's topography trend is the primary driver influencing the distribution of river tributaries, and the water exchange amount has a decreasing trend from upstream to downstream of the main river channel.
\end{abstract}

\section{Introduction}

A hyporheic zone is an active ecotone which connects the surface water and groundwater [1]. It is characterized by the hydrological, chemical, biological [2], hydrogeological [3], and biogeochemical features [4]. Studies of hyporheic zones have been significantly increased in recent years (Figure 1).

Water exchange is a fundamental interest in the energy transport of a hyporheic zone [5]. That is associated with the substantial transient including heat and dissolved and suspended substances, as well as physicochemical processes $[1,6,7]$. The spatiality of water exchange at the stream-aquifer interface has important implications for the fate and transport of contaminants in river basins [8]. Therefore, hyporheic water exchange (HWE) provides hydrogeological information about the interactions between groundwater and surface groundwater, whose function is crucial to the overall riverine ecosystem.
However, the interaction between groundwater and surface water has been regarded as two distinct entities and focused on the distinction of within system and inner single objects for a long period [9]. In reality, interactions in this zone are more complex and have the importance of the water quality $[10,11]$. This process is influenced by the spatial variation of hydrologic conditions such as topographic relief and regional scale [12]. An accurate estimate of HWE at catchment scale is challenging, in terms of hydrological heterogeneity $[1,13-15]$. Therefore, the new sight to couple groundwater and surface water as an integrated system to estimate the water exchange is essential for the management of fluvial and lotic systems.

Numerous methods have been used to assess stream and groundwater interaction [16]. They can be classified into seepage meters, hydrological elements, numerical model, remote sensing, and tracer method. The bag-type seepage meter has been widely used to estimate water exchange in 


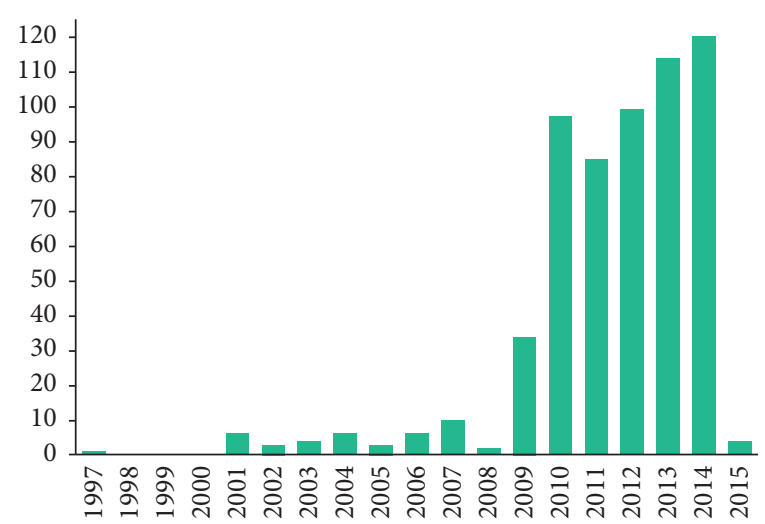

FIGURE 1: Number of citations of papers on hyporheic zone since 1997, based on a search in the ISI Web of Science (http://apps.webofknowledge.com/CitationReport.do?product=UA\&search_mode=CitationReport\&SID=Z2Y7ku9pWciBC3oHJF3\&page=1 \&cr_pqid=3\&viewType=summary).

lakes, estuaries, reservoirs, and streams [17]. But the seepage meter's success has been limited by operational problems during field work [18]. Water velocity can be deducted using solute travel time and distance data. The relationship between water temperature and the water velocity has been used to calculate the water exchange from the groundwater into streams [13]. The application of contaminants modeling has developed the theory and simulation technique $[19,20]$. Remote sensing provides the new approach to investigate the water exchange [21]. New technologies are increasingly used to measure HWE such as distributed temperature sensing [22, 23]. The tracer method, such as calcium chloride, salt, and dye, has frequently been used to estimate the water exchange in hyporheic zone [16]. Heat, as a natural tracer, has been used to simulate HWE owing to temperature distribution; on the one hand, it is the result of heat conduction in the subsurface, but also it is the consequence of the advection movement of water through the porous medium [24]. Hence water fluxes between groundwater and surface water can be estimated by measuring temperature distributions within the coupled systems $[25,26]$. However, studies using heat as a water exchange estimator have mainly measured temperature within a single stream or in one segment of a river. The water exchange in a hyporheic zone at catchment scale is poorly understood and needs further investigation. Moreover, for the Weihe River, which is long and crosses different topographic classes, interactions between the surface water and groundwater in the mainstream channel and its tributaries have been relatively unknown.

Using heat as a tracer to investigate HWE in the Weihe River extends the application of the thermal method to the catchment scale. The principal foci of this study are to investigate the water exchange across the large basin scale and find the relationship between the exchange and the spatial distribution of rivers. The objectives of the paper are (1) to detect patterns of water exchange in the hyporheic zone, (2) to quantify the rate of hyporheic water exchange, and (3) to describe the spatial variability of HWE at catchment scale.
TABLE 1: Testing sites and the abbreviations in this study.

\begin{tabular}{lccccc}
\hline Testing site & Meixian & Xi'an & Lintong & Huaxian & Hengshuihe \\
Abbreviation & MX & XA & LT & HX & HSH \\
\hline Testing site & Heihe & Laohe & Juehe & Tangyuhe & Beiluohe \\
Abbreviation & HH & LH & JH & TYH & BLH \\
\hline
\end{tabular}

\section{Study Area Description}

As the largest tributary of the Yellow River, the Weihe River plays a vital role in water supply and agricultural development in Guanzhong Basin. The Weihe River originates from Gansu Province, China, from where it flows eastward through Shaanxi Province, and, at Tongguanxian in the east of Shaanxi Province, it merges into the Yellow River. The river has a total length of $818 \mathrm{~km}$ and a drainage area of $13.4 \times 10^{4} \mathrm{~km}^{2}$. The whole river has a longitudinal inclination of about $1.7 \%$. The drainage area and transportation of the sediments of this river account for $17.9 \%$ and $2.5 \%$ for the Yellow River [27], respectively. The Weihe River flows along the northern Qinling Mountains in Shaanxi Province, which have an altitude of $1500-3000 \mathrm{~m}$.

Ten study sites across catchment were chosen for this study (Figure 2). Four sites are located along the main channel, while the rest of the tributaries are secondary and tertiary rivers. The Beiluo River is the largest tributary of the Weihe River. Some sites allocated in the southern tributaries are stemmed from Qinling Mountains. The climate and vegetation are distinctive on north and south sides; loess has preserved well on the eastern side [28]. Table 1 lists the testing sites and abbreviations in this study. At those sites, the components of the deposits along the study bank differ from fluvial sand, silt, clay, coarsegrained sediments, and gravels. During annual flood periods, which occur in late autumn, the river carries about two to three times more water than the average mean recharge. 


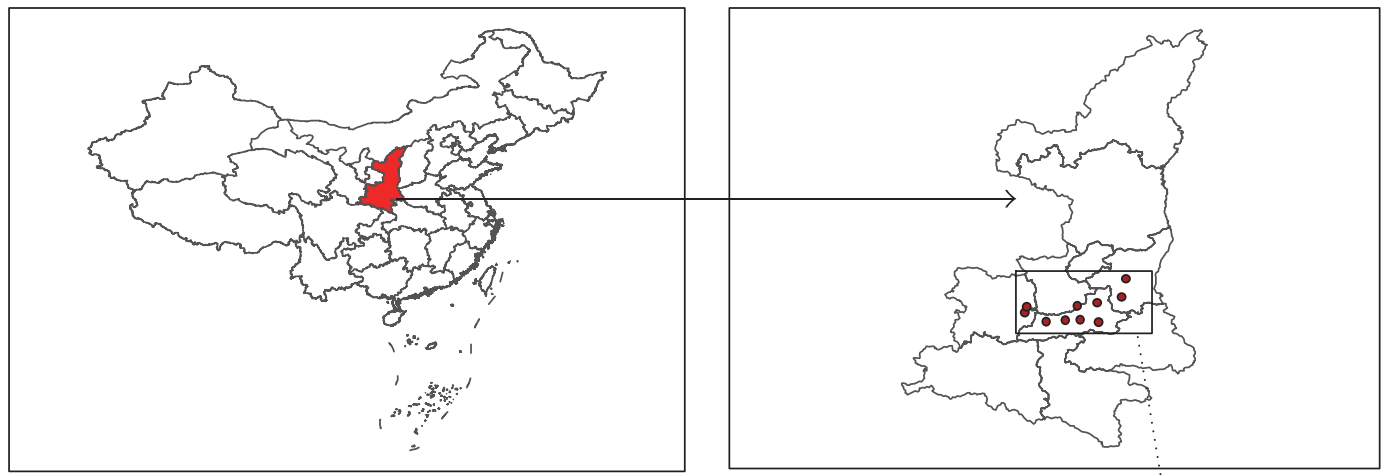

(a)

(b)

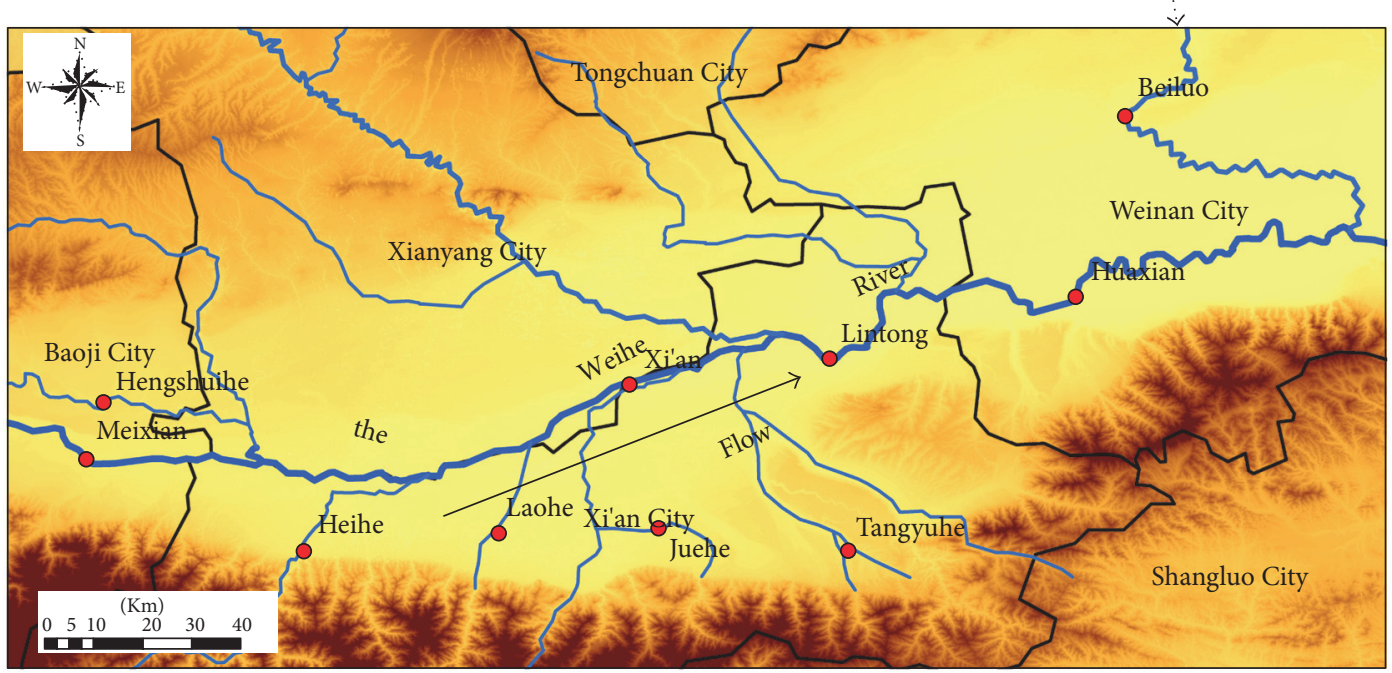

$\begin{array}{ll} & \text { Elevation in meter } \\ \text { Test sites } & \text { High: } 3754 \\ \text { Rivers } & \text { - Low: } 206\end{array}$

(c)

FIGURE 2: Location map of testing sites in this study.

\section{Methods}

3.1. Sediment Temperatures Collection. The measurements were taken during the summer of 2013. A two-meter thermal bar with a small flat plate at the upper end and a pointed tip at the bottom end (Figure 3) was utilized to measure sediments temperature. This design allows the thermistor to be inserted into the sediment easily. Measurements of streambed temperature were collected at multiple depths at each location (various depths: $0,0.1,0.2,0.35,0.5$, and $0.7 \mathrm{~m}$ ), the data were collected 15 minutes after the temperature kept stable, and then temperature profiles in the hyporheic zone were plotted.

Measurement of the sediment temperature was carried out along one side of the riverbank. Thus the field points were allocated to a relatively shallow area of the river. The distance interval between each point was about 10 meters. There was a range of around 1.5-meter distance away from the bank side of the river (Figure 3).

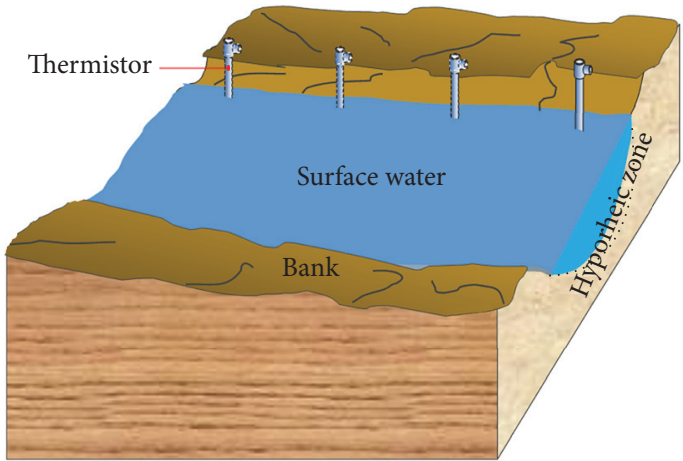

Figure 3: Collection of the temperature data along one side of the river.

3.2. Water Exchange Modeling. The transportation of energy in the hyporheic zone involves sediment conductivities and water percolation [24]. Assuming the sediment has uniform 
distribution, and the water exchanges only occur in a vertical direction (upward or downward), the one-dimensional thermal equation can be used to calculate the water transfer as follows [29]:

$$
\frac{K}{\rho c} \frac{\partial^{2} T(z)}{\partial z^{2}}-\frac{v \rho_{0} c_{0}}{\rho c} \frac{d T(z)}{d z}=\frac{\partial T(z)}{\partial t},
$$

where $v$ is vertical water exchange in the sediments at depth $z(\mathrm{~mm} / \mathrm{d}), T(z)$ is the temperature $\left({ }^{\circ} \mathrm{C}\right)$ of the streambed sediments at $z$-depth, and $\rho c$ and $\rho_{0} c_{0}$ are the volumetric heat capacity of saturated streambed system $\left(\mathrm{J} \mathrm{m}^{-3} \mathrm{~K}^{-1}\right)$ and the volumetric heat capacity of the fluid $\left(\mathrm{J} \mathrm{m}^{-3} \mathrm{~K}^{-1}\right)$, respectively. Moreover, $K$ is the thermal conductivity of the solid-fluid system $\left(\mathrm{J} \mathrm{s}^{-1} \mathrm{~m}^{-1} \mathrm{~K}^{-1}\right)$.

In thermal steady-state conditions, the right-hand of (1) tends to 0 and can be written as follows [18]:

$$
\frac{\partial^{2} T(z)}{\partial z^{2}}-\frac{v \rho_{0} c_{0}}{K} \frac{d T(z)}{d z}=0 .
$$

With the assumption that there is a quasi-constant groundwater temperature at depth and assuming the boundary conditions $T=T_{0}$ for $z=0$, and a fixed temperature $T_{L}$ for $z=L$, the temperature profile can be fitted by the analytical steady-state solution of one-dimensional heat transport equation [24], then the solution of Eq. (2) can be written as:

$$
v=\left|\frac{K}{\rho_{0} c_{0} z} \ln \frac{T(z)-T_{L}}{T_{0}-T_{L}}\right|
$$

Using this equation to quantify the vertical water exchange $v(\mathrm{~mm} / \mathrm{d})$, the performance of this method has the following advantages: (1) it can be used with relatively small data; (2) it has high measurement efficiency in the field work [14]; (3) it was a steady-state thermal-flux model [18]. Considering the cost of data measurements in many locations, the ten sites across the large basin can provide catchment scale benefits.

3.3. Determination of Hyporheic Water Exchange Patterns. HWE patterns can be illustrated using a conceptually simplified diagram (Figure 4). The line "(a)" indicates the upward flux into the surface water; the line "(b)" shows the downward flux into the groundwater. The details of the conceptual diagram were described in some previous studies $[18,26]$.

\section{Results}

4.1. Sediment Temperatures. The statistical analyses of the temperatures at different testing sites are shown in Figure 5. For the ten investigated sites, the maximum and the minimum temperatures of the sediment are $33^{\circ} \mathrm{C}$ and 18.2, respectively. The difference between the highest and lowest is $14.8^{\circ} \mathrm{C}$. The average temperature difference between the upper layer and the deepest layer is $4^{\circ} \mathrm{C}$. The maximum residual of the stratification sediment is $2.5^{\circ} \mathrm{C}$, and the minimum of the residual is $0.07^{\circ} \mathrm{C}$.

The average temperature of the deposits in the upper boundary is $28.1^{\circ} \mathrm{C}$, while the temperature at the deepest

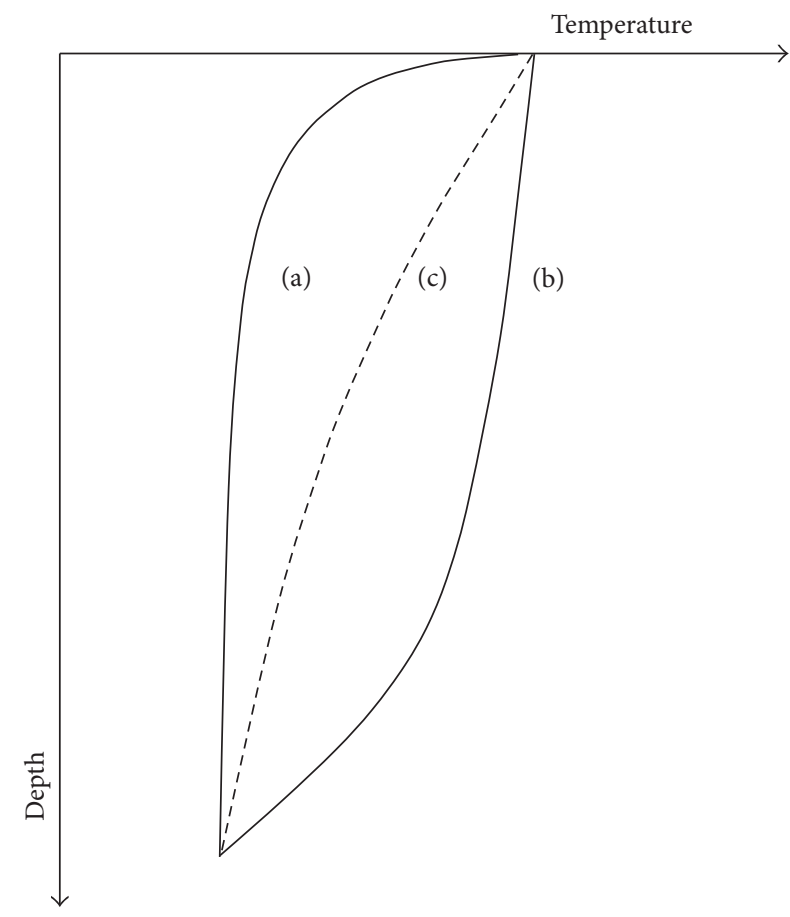
(a) Discharge
(b) Recharge
(c) Steady state

FIgURE 4: The simplified schematic diagram to determine the water exchange patterns.

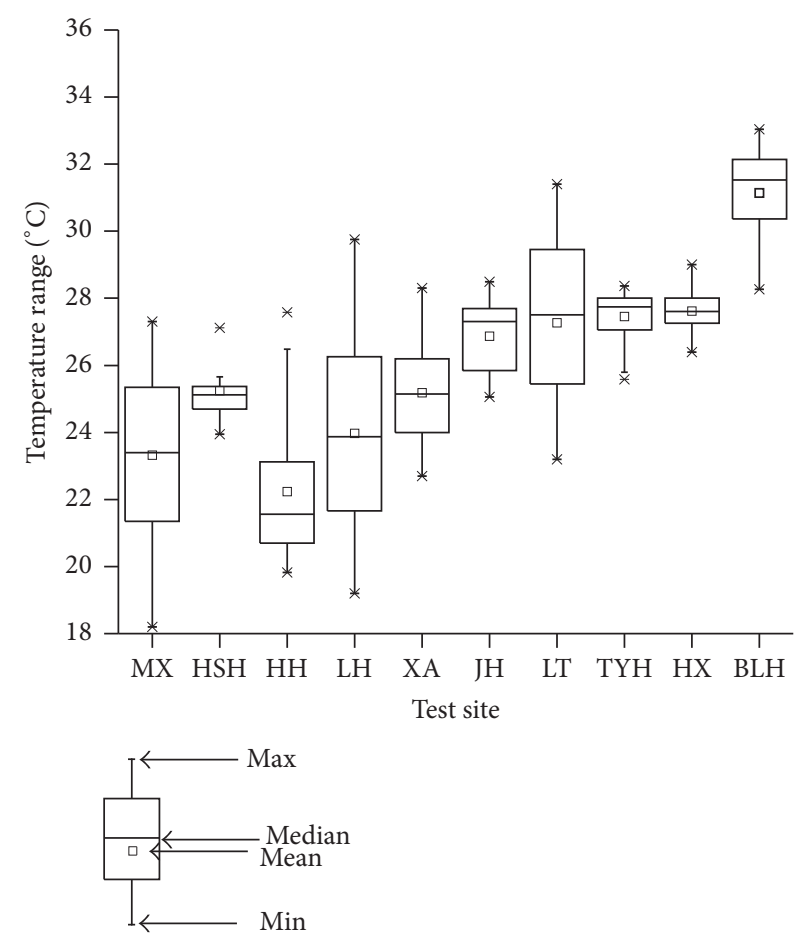

FIgURE 5: Box plot of sediment temperatures in testing sites. 


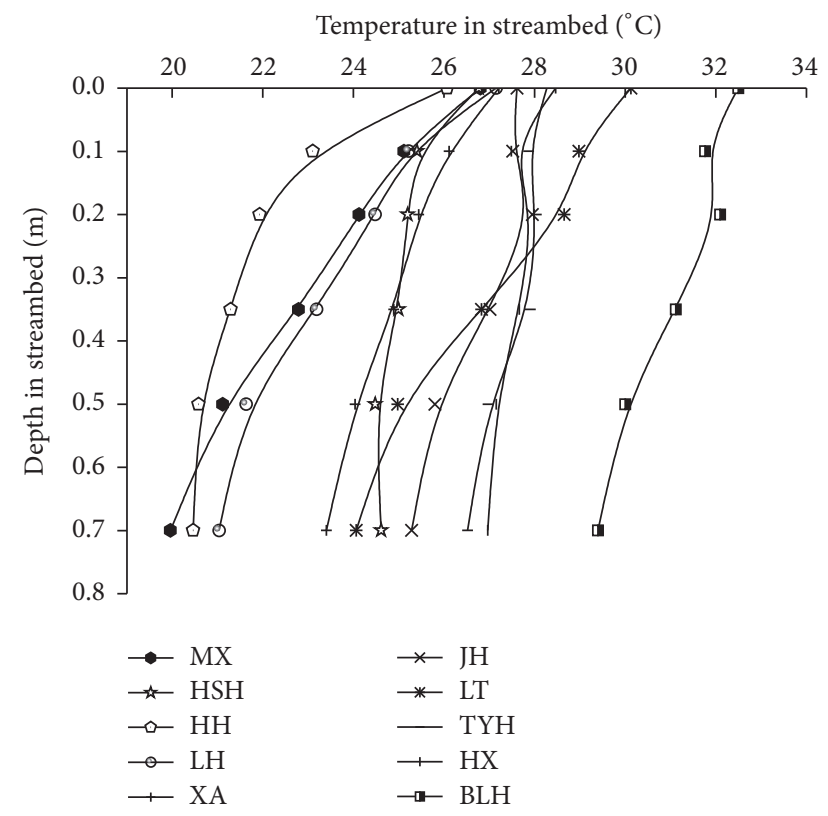

Figure 6: Temperature profiles of streambed sediment in testing sites.

depth is $24.1^{\circ} \mathrm{C}$. The difference of temperature ranges from $8.9^{\circ} \mathrm{C}$ in $\mathrm{MX}$ to $2.5^{\circ} \mathrm{C}$ in $\mathrm{LH}$.

4.2. Distribution of Temperatures. Figure 6 shows the variation of the temperature-depth profiles for the sediments in the different segments of the river. For the temperature-depth profiles at each testing site, the whole trend of changes is similar. However, the shape of the profiles displays a dissimilar tendency at certain depths. For instance, the profiles have relative tremendous changes in $\mathrm{JH}, \mathrm{HX}$, and TYH.

The results show a distinct gradient of temperature profiles among the testing sites. In the summer season, the diffusion of the temperature variations differs in the segments of the river; the sediment temperatures decreased as the water became deeper. Sediment temperature can be categorized into five classifications using the change of temperature gradient: (1) rivers that had an extreme change of the temperature including the HX and TYH; (2) rivers that had a moderate degree of the temperature changes including $\mathrm{JH}$ and BLH; (3) rivers that had good temperature profiles including $\mathrm{HH}$ and $\mathrm{HSH}$; (4) rivers that had a weak changed profile including MX and $\mathrm{LH}$; and (5) rivers that had a stable change profile, XA, and LT.

4.3. Hyporheic Water Exchange. The maximum rate of water exchange is $78.7 \mathrm{~mm} / \mathrm{d}$, which occurred in the $\mathrm{HH}$, and the minimum of the median is $27.56 \mathrm{~mm} / \mathrm{d}$ which occurs in $\mathrm{JH}$, which is one of the second-order tributaries and is in the southern part of the Weihe River.

The water exchange along the Weihe River has apparent spatial variability from the upstream to downstream; the water exchange at MX in upstream location is close to two times greater than tributaries in middle reaches of the river such as the JH and TYH (Figure 7(a)).
Figure 7 shows the relationship between the HWE and the average temperature from the upstream to downstream. For the average temperature, the sediment temperature increased with the distance away from the upstream; however, the median of the water exchange was greater downstream. The spatial correlation coefficient $R^{2}$ of the water exchange and average temperature is 0.62 and 0.84 , respectively. We can find that the water exchange has a close correlation with the distance from the upstream. Secondly, the tributaries also had the same pattern on the southern river. Furthermore, all the testing sites were compared, and there is good agreement overall (Figure 7). The trend demonstrates the general distribution of water exchange in variations across the catchment.

\section{Discussion}

5.1. Temperature Spatiality. Temperature has increasing tendency from the upstream to downstream (Figure 7(b)). The hydrological heterogeneity leads to the spatial characteristics of different segments of the river. Spatial variations of the sediment could result in the spatial changes of the streambed temperature. Previous studies found that sediments structure has an impact on thermal transportation [30]. The sediment temperature is influenced by hydraulic conditions, sediments temperature with relevance to the conductivity of the heat transport of the fluid, and solid mixing textures. Additionally, the temperature of streambed sediments was affected by the changes in atmospheric temperature and radiation from the center of the earth and has the diurnal and seasonal variations [26]. For instance, the spatial structure of the microtopography from some transects in the catchment influenced the distributions of the elevation classes and affected the allocation of the temperature in the sediments [31]. Fluxes and residence times varied in different geomorphic features such as streams in mountain regions [20]. Moreover, some studies have investigated flow path status in the hyporheic zone; the exit and reenter phenomenon would take place within ten meters $[32,33]$ and displayed that the variations of upward flux would influence the streambed temperatures measured over a short period at many locations [34].

In summary, the temperatures at the testing sites have the negative agreement with the depth. However, the temperatures have the apparent gradient oscillations in certain ranges. This range is mainly concentrated around a depth of $20 \mathrm{~cm}$. In this case, the steady state of the heat transport is disturbed by the sediments properties and hydrologic conditions. The temperature in the sediments was not good satisfying the quasit-steady-state condition in these depth ranges. In those ranges, HWE would be more strongly influenced by water flowing from other directions or the heterogeneity of the sediment. This pattern of temperature distribution reflects the highly variable amplitude ratio values in this content. The complexity of geomorphic features in particular reaches caused a series of related complex flow pathways in the hyporheic zone, which means the water exchange varies in both magnitude and direction [35]. 


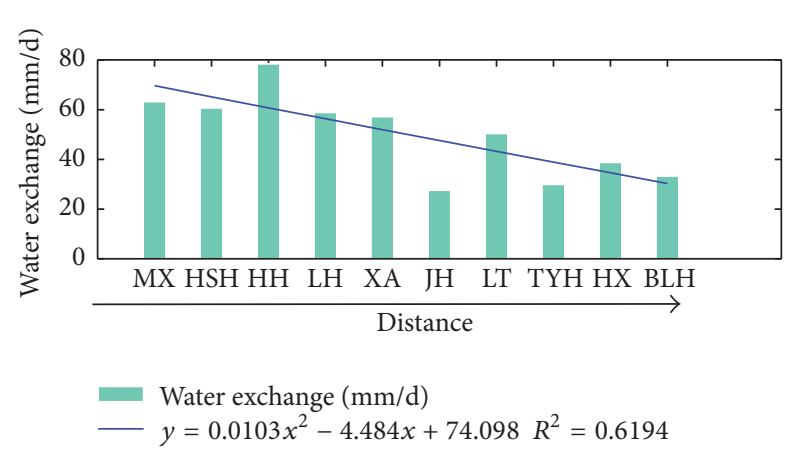

(a)

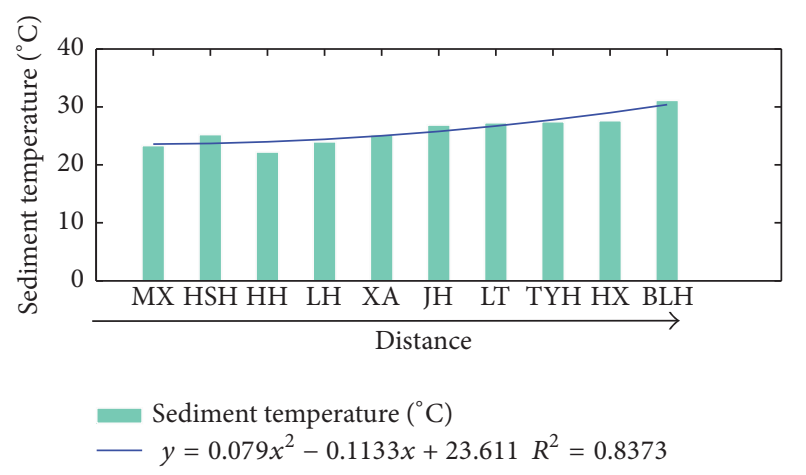

(b)

FIGURE 7: The treads of hyporheic water exchange and temperature with the upstream of the Weihe River.

\subsection{Hyporheic Water Exchange Patterns. Interactions bet-} ween surface water and groundwater can be identified using a conceptual model (Figure 4). Generally, water interaction is mainly from groundwater to surface water.

HWE has the distributional patterns in space, the variables of the water exchange influence the inflows and outflows processes [36], and, to a great catchment scale, those hugely amplified the water exchange magnitude by even some orders. However, in this study, for the median of water exchange, the difference for the water exchange magnitude does not reach several orders. The maximum is about three times the minimum. The extreme values all exist in secondary tributaries of the river flowing in the mountains. This may be related to more complex morphologic attributes underlying the surface water.

5.3. Controlling Drivers of Hyporheic Water Exchange. The medians of HWE compared to the distance away from the upstream in space (Figure $7(\mathrm{a})$ ). The water exchange in different stream reaches of the stream corresponds to the creek features from upstream to downstream.

Many factors are influencing the water exchange in the hyporheic zone, such as the hydraulic conductivity, sediment component, sediment grain size, and the discharge from the groundwater [37]. The spatial distribution of water exchange has a high correlation to the topographic patterns and the local space [38]. In the downstream reaches, other factors are controlling the HWE; for example, in meandering river channels, the horizontal flow through the streambed may be contributing to complex flow [35].

The hyporheic water exchange is associated with the local streambed attributes (i.e., sediment structure and topography) [6]. In hydrological processes, the heterogeneities of the sediments influence water exchange, and both the water exchange and other transient processes have a heterogeneous spatial distribution [39]. The deposit structure with the wood or other materials could create a heterogeneous streambed, the fine sediments of the streambed. Generally, the water exchange is relatively smaller than the heterogeneities of the streambed [40].

Vegetation is another driver influencing the water exchange in the hyporheic zone. There are relatively good vegetated plants around the Heihe environment; the plants are, especially, central great high trees. In summer, water head change is due to pumping function from vegetation [41].

It should be noted that the human constructions also influence the HWE processes. In TYH, the measurements of the location are about 50 meters from the dam, which has been blocked by fine silt and gravel. Therefore, in this environment, the hydraulic conductivity tends to be small, and the sediment has the uniform texture with little heterogeneity. As a result, HWE tends to be low. For some deposits with a particular volume close to surface water, there was no good steady state due to the sediments influenced by fluctuations from surface water flow. The exchange energy of HWE will control the water transfer pattern in the individual range [42]. Where there are variations at sites only in some meters apart, this probably represents outflow within the hyporheic zone [36]. If the water transfer occurs in finegrained upper sediments, a shallow impermeable layer can be created and thus leads to the changes in water exchange patterns.

5.4. Hyporheic Water Exchange Scales. The HWE dimensional scales influence the spatial patterns of the river to some degree. The HWE can be categorized into two scales based on its driving processes, which are large-scale and smallscale [6]. Large-scale hydrological exchange results from the spatial and temporal differences between the stream and the surrounding groundwater levels. The small-scale exchange is mainly driven by the hydrologic flow conditions and the morphological features of the streambed [7]. For instance, the small slope and the irregular streambed of a riffle-pool sequence beneath the stream are not perceptible [20,25], meaning the topographic changes in the streambed and the elevation of the surface water would lead to the surface water discharge and connect with groundwater [34]; these structures enhanced the complex dynamics between groundwater and surface water. Streambeds with highly permeable bed sediments have apparent vertical water exchange $[36,43]$. In this study, the HWE has the same trend with the hydraulic conductivity in the main channel of the river.

Furthermore, the no-parameter test of Kruskal-Wallis was used to evaluate the difference between the HWE amount 
in the main channel and its tributaries. The $P$ value of the water exchange magnitude was close to 0.4 , and this highlights the spatial difference in the catchment.

\section{Conclusions}

The one-dimensional equation was used to estimate hyporheic water exchange and evaluate its spatial distribution in the Weihe River catchment. The thermal method is an easy, cheap, and robust way to obtain temperature variations. This approach provides spatial information that could be substantial when estimating the interaction between groundwater and surface water.

Our findings show that the hyporheic water exchange has spatial variations across the catchment. The exchange magnitude has a decreasing tendency from the upstream to downstream, which is controlled by the distance away from the downstream. The hyporheic water exchange trend has a consistency with the main river channel. The complexity of water exchange takes place in the southern tributaries in mountainous regions. The rate of the water exchange tends to be the underestimate because of only consideration in vertical fluxes. In the future investigation, some new parameters will be encouraged to improve the accuracy of the estimation on hyporheic water exchange.

\section{Conflicts of Interest}

The authors declare that there are no conflicts of interest and funding regarding the publication of this paper.

\section{Acknowledgments}

This work was support by National Natural Science Foundation of China (Grant nos. 51379175 and 51679200 ), Specialized Research Fund for the Doctoral Program of Higher Education (Grant no. 20136101110001), Program for Key Science and Technology Innovation Team in Shaanxi Province (Grant no. 2014KCT-27), and The Hundred Talents Project of the Chinese Academy of Sciences (Grant no. A315021406). The authors thank Jiaxuan Li, Xiaojuan Li, Xiaogang Yang, and other members for assistance in field sampling and laboratory experiments.

\section{References}

[1] M. Brunke and T. Gonser, "The ecological significance of exchange processes between rivers and groundwater," Freshwater Biology, vol. 37, no. 1, pp. 1-33, 1997.

[2] J. A. Stanford and J. V. Ward, "The hyporheic habitat of river ecosystems," Nature, vol. 335, no. 6185, pp. 64-66, 1988.

[3] F. J. Triska, V. C. Kennedy, R. J. Avanzino, G. W. Zellweger, and K. E. Bencala, "Retention and transport of nutrients in a thirdorder stream in northwestern California; hyporheic processes," Ecology, vol. 70, no. 6, pp. 1893-1905, 1989.

[4] P. J. Hancock, A. J. Boulton, and W. F. Humphreys, "Aquifers and hyporheic zones: towards an ecological understanding of groundwater," Hydrogeology Journal, vol. 13, no. 1, pp. 98-111, 2005.
[5] A. Argerich, E. Martí, F. Sabater, and M. Ribot, “Temporal variation of hydrological exchange and hyporheic biogeochemistry in a headwater stream during autumn," Journal of the North American Benthological Society, vol. 30, no. 3, pp. 635-652, 2011.

[6] M. Mutz and A. Rohde, "Processes of surface-subsurface water exchange in a low energy sand-bed stream," International Review of Hydrobiology, vol. 88, no. 3-4, pp. 290-303, 2003.

[7] A. J. Boulton, S. Findlay, P. Marmonier, E. H. Stanley, and H. Maurice Valett, "The functional significance of the hyporheic zone in streams and rivers," Annual Review of Ecology and Systematics, vol. 29, pp. 59-81, 1998.

[8] E. Kalbus, C. Schmidt, M. Bayer-Raich et al., "New methodology to investigate potential contaminant mass fluxes at the stream-aquifer interface by combining integral pumping tests and streambed temperatures," Environmental Pollution, vol. 148, no. 3, pp. 808-816, 2007.

[9] T. C. Winter, J. W. Harvey, F. O. Lehn, and W. M. Alley, Ground Water and Surface Water: A Single Resource, Diane Publishing Co, Collingdale, Pa, USA, 1999.

[10] M. Kumarasamy, "Simulation of stream pollutant transport with hyporheic exchange for water resources management," in Current Issues of Water Management, InTech, 2011.

[11] M. Sophocleous, "Interactions between groundwater and surface water: the state of the science," Hydrogeology Journal, vol. 10 , no. 1, pp. 52-67, 2002.

[12] G. Jin, H. Tang, L. Li, and D. A. Barry, "Hyporheic flow under periodic bed forms influenced by low-density gradients," Geophysical Research Letters, vol. 38, no. 22, 2011.

[13] M. W. Becker, T. Georgian, H. Ambrose, J. Siniscalchi, and K. Fredrick, "Estimating flow and flux of ground water discharge using water temperature and velocity," Journal of Hydrology, vol. 296, no. 1-4, pp. 221-233, 2004.

[14] J. Keery, A. Binley, N. Crook, and J. W. N. Smith, “Temporal and spatial variability of groundwater-surface water fluxes: development and application of an analytical method using temperature time series," Journal of Hydrology, vol. 336, no. 12, pp. 1-16, 2007.

[15] W. W. Woessner, "Stream and fluvial plain ground water interactions: rescaling hydrogeologic thought," Ground Water, vol. 38, no. 3, pp. 423-429, 2000.

[16] E. Kalbus, F. Reinstorf, and M. Schirmer, "Measuring methods for groundwater-surface water interactions: a review," Hydrology and Earth System Sciences, vol. 10, no. 6, pp. 873-887, 2006.

[17] S. A. Isiorho and J. H. Meyer, "The effects of bag type and meter size on seepage meter measurements," Ground Water, vol. 37, no. 3, pp. 411-413, 1999.

[18] C. Anibas, K. Buis, R. Verhoeven, P. Meire, and O. Batelaan, "A simple thermal mapping method for seasonal spatial patterns of groundwater-surface water interaction," Journal of Hydrology, vol. 397, no. 1-2, pp. 93-104, 2011.

[19] E. Schwegler, J. C. Grossman, F. Gygi, and G. Galli, “Towards an assessment of the accuracy of density functional theory for first principles simulations of water. II," Journal of Chemical Physics, vol. 121, no. 11, pp. 5400-5409, 2004.

[20] T. Kasahara and S. M. Wondzell, "Geomorphic controls on hyporheic exchange flow in mountain streams," Water Resources Research, vol. 39, no. 1, pp. SBH 3-1-SBH 3-14, 2003.

[21] S. P. Loheide II and S. M. Gorelick, "Quantifying streamaquifer interactions through the analysis of remotely sensed thermographic profiles and in situ temperature histories," Environmental Science and Technology, vol. 40, no. 10, pp. 3336-3341, 2006. 
[22] J. H. Fleckenstein, S. Krause, D. M. Hannah, and F. Boano, "Groundwater-surface water interactions: new methods and models to improve understanding of processes and dynamics," Advances in Water Resources, vol. 33, no. 11, pp. 1291-1295, 2010.

[23] C. S. Lowry, J. F. Walker, R. J. Hunt, and M. P. Anderson, "Identifying spatial variability of groundwater discharge in a wetland stream using a distributed temperature sensor," Water Resources Research, vol. 43, no. 10, Article ID W10408, 2007.

[24] C. Anibas, J. H. Fleckenstein, N. Volze et al., "Transient or steady-state? Using vertical temperature profiles to quantify groundwater-surface water exchange," Hydrological Processes, vol. 23, no. 15, pp. 2165-2177, 2009.

[25] E. Kalbus, C. Schmidt, J. W. Molson, F. Reinstorf, and M. Schirmer, "Influence of aquifer and streambed heterogeneity on the distribution of groundwater discharge," Hydrology and Earth System Sciences, vol. 13, no. 1, pp. 69-77, 2009.

[26] M. P. Anderson, "Heat as a ground water tracer," Ground Water, vol. 43, no. 6, pp. 951-968, 2005.

[27] Q. Li, J. X. Song, A. L. Wei, and B. Zhang, "Changes in major factors affecting the ecosystem health of the Weihe River in Shaanxi Province, China," Frontiers of Environmental Science and Engineering, vol. 7, no. 6, pp. 875-885, 2013.

[28] H. Zhang, H. Lu, S.-Y. Jiang, J. Vandenberghe, S. Wang, and R. Cosgrove, "Provenance of loess deposits in the Eastern Qinling Mountains (central China) and their implications for the paleoenvironment," Quaternary Science Reviews, vol. 43, pp. 94-102, 2012.

[29] S. Suzuki, "Percolation measurements based on heat flow through soil with special reference to paddy fields," Journal of Geophysical Research, vol. 65, no. 9, pp. 2883-2885, 1960.

[30] M. M. Krol, R. L. Johnson, and B. E. Sleep, "An analysis of a mixed convection associated with thermal heating in contaminated porous media," Science of the Total Environment, vol. 499, pp. 7-17, 2014.

[31] S. Frei, G. Lischeid, and J. H. Fleckenstein, "Effects of microtopography on surface-subsurface exchange and runoff generation in a virtual riparian wetland-a modeling study," Advances in Water Resources, vol. 33, no. 11, pp. 1388-1401, 2010.

[32] R. G. Storey, K. W. F. Howard, and D. D. Williams, "Factors controlling riffle-scale hyporheic exchange flows and their seasonal changes in a gaining stream: a three-dimensional groundwater flow model," Water Resources Research, vol. 39, no. 2, p. 1034, 2003.

[33] G. J. Wroblicky, M. E. Campana, H. M. Valett, and C. N. Dahm, "Seasonal variation in surface-subsurface water exchange and lateral hyporheic area of two stream-aquifer systems," Water Resources Research, vol. 34, no. 3, pp. 317-328, 1998.

[34] B. Conant Jr., "Delineating and quantifying ground water discharge zones using streambed temperatures," Ground Water, vol. 42, no. 2, pp. 243-257, 2004.

[35] R. M. Fanelli and L. K. Lautz, "Patterns of water, heat, and solute flux through streambeds around small dams," Ground Water, vol. 46, no. 5, pp. 671-687, 2008.

[36] X. Chen, J. Song, C. Cheng, D. Wang, and S. O. Lackey, "A new method for mapping variability in vertical seepage flux in streambeds," Hydrogeology Journal, vol. 17, no. 3, pp. 519-525, 2009.

[37] C. Baxter, F. R. Hauer, and W. W. Woessner, "Measuring groundwater-stream water exchange: new techniques for installing minipiezometers and estimating hydraulic conductivity," Transactions of the American Fisheries Society, vol. 132, no. 3, pp. 493-502, 2003.
[38] A. S. Ward, M. Fitzgerald, M. N. Gooseff, T. J. Voltz, A. M. Binley, and K. Singha, "Hydrologic and geomorphic controls on hyporheic exchange during base flow recession in a headwater mountain stream," Water Resources Research, vol. 48, no. 4, Article ID W04513, 2012.

[39] F. Boano, R. Revelli, and L. Ridolfi, "Effect of streamflow stochasticity on bedform-driven hyporheic exchange," Advances in Water Resources, vol. 33, no. 11, pp. 1367-1374, 2010.

[40] M. Salehin, A. I. Packman, and M. Paradis, "Hyporheic exchange with heterogeneous streambeds: laboratory experiments and modeling," Water Resources Research, vol. 40, no. 11, Article ID W11504, pp. 1-16, 2004.

[41] P. Wang, Y. Zhang, J. Yu, G. Fu, and F. Ao, "Vegetation dynamics induced by groundwater fluctuations in the lower Heihe River Basin, northwestern China," Journal of Plant Ecology, vol. 4, no. 1-2, pp. 77-90, 2011.

[42] G. Q. Jin, H. W. Tang, B. Gibbes, L. Li, and D. A. Barry, "Transport of nonsorbing solutes in a streambed with periodic bedforms," Advances in Water Resources, vol. 33, no. 11, pp. 14021416, 2010.

[43] J. W. Harvey and K. E. Bencala, “The Effect of streambed topography on surface-subsurface water exchange in mountain catchments," Water Resources Research, vol. 29, no. 1, pp. 89-98, 1993. 

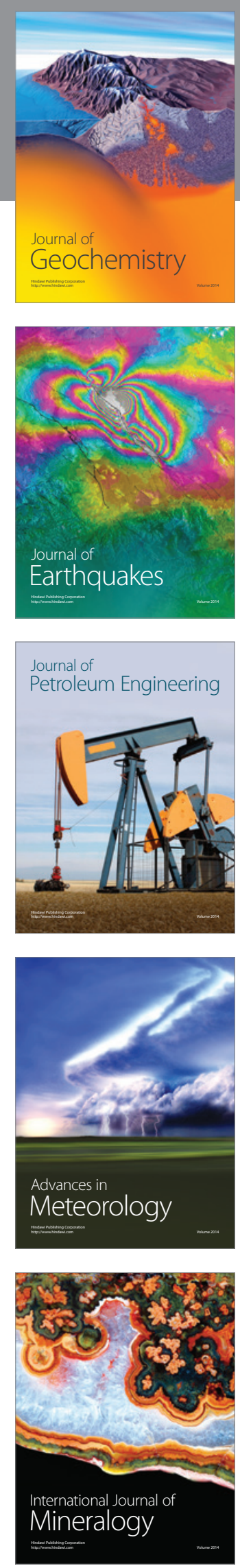
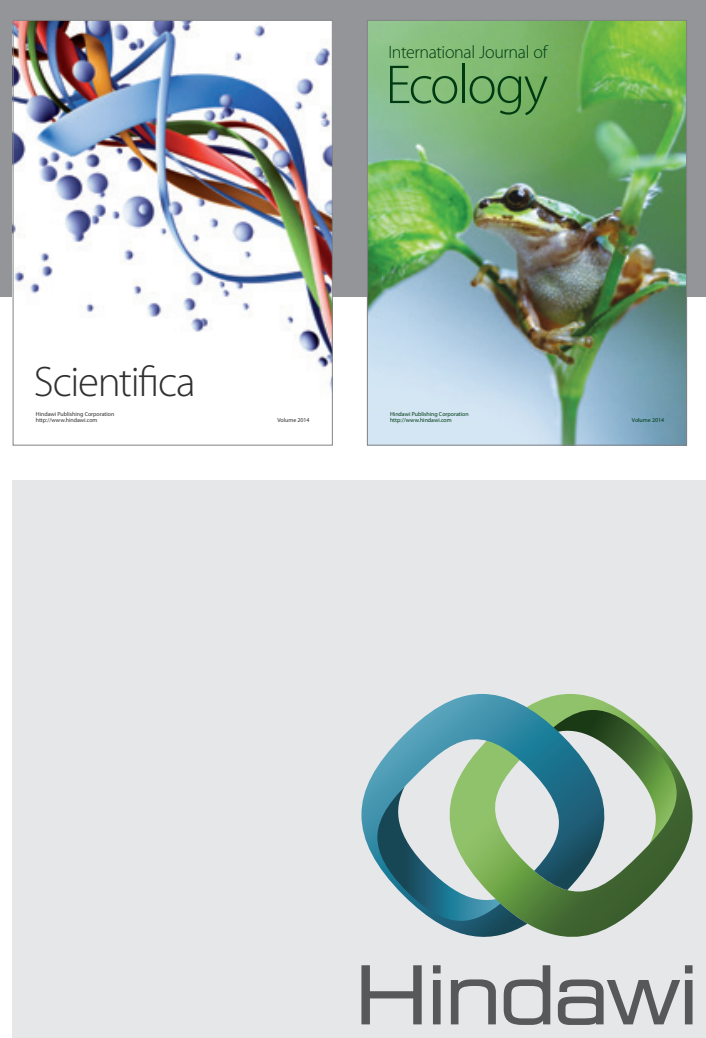

Submit your manuscripts at

https://www.hindawi.com
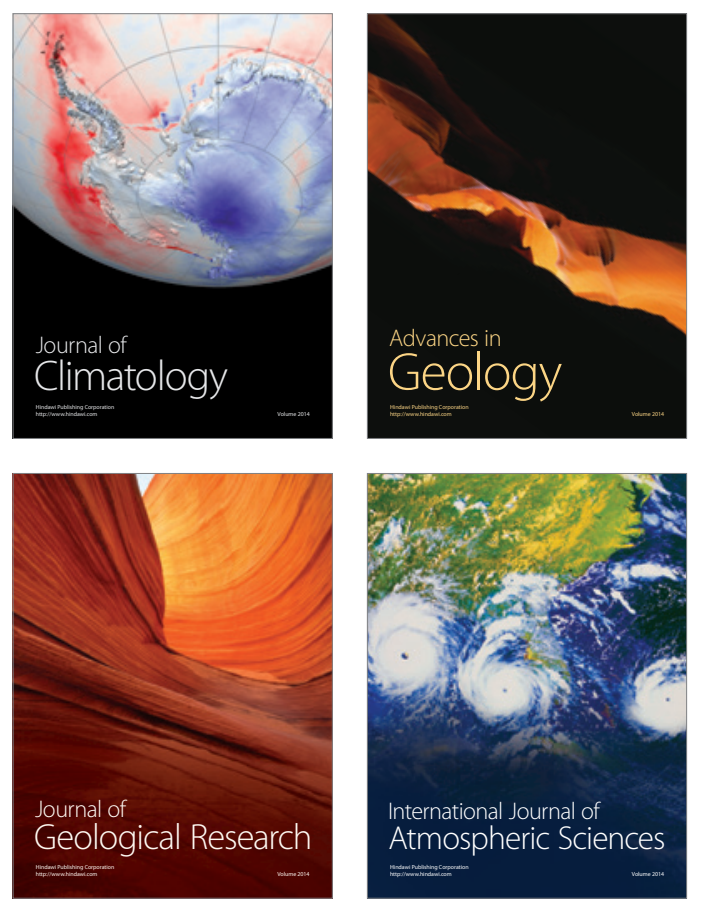

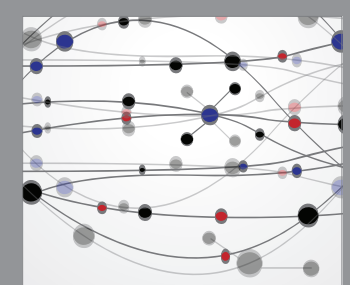

The Scientific

\section{World Journal}
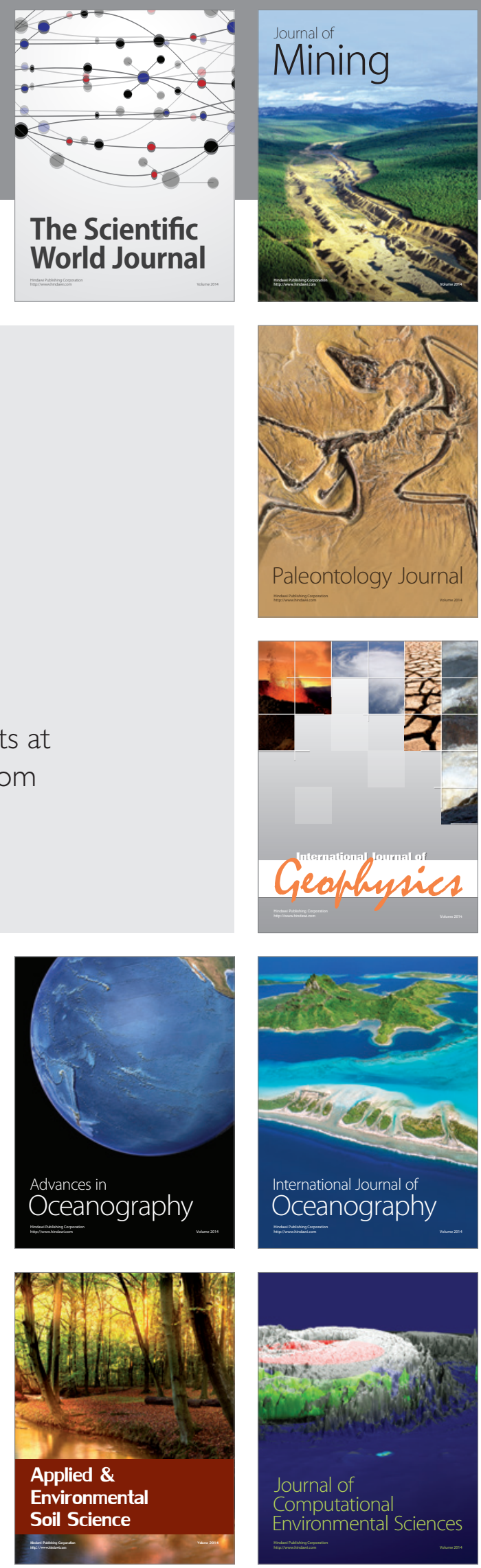